Published in final edited form as:

World J Surg. 2009 September ; 33(9): 1836-1841. doi:10.1007/s00268-009-0113-4.

\title{
Epidemiology of Injuries at a Tertiary Care Center in Malawi
}

\author{
Jonathan C. Samuel, \\ Department of Surgery, University of North Carolina, Chapel Hill, NC 27599, USA \\ Department of Surgery, Kamuzu Central Hospital, P.O. Box 149, Lilongwe, Malawi
}

Adesola Akinkuotu,

School of Medicine, University of North Carolina, Chapel Hill, NC 27599, USA

\begin{abstract}
Andres Villaveces,
Department of Epidemiology, School of Public Health, University of North Carolina, Chapel Hill, NC 27599, USA

Injury Prevention Research Center, University of North Carolina, 137 East Franklin Street, CB 7505 Chapel Hill, NC 27599, USA
\end{abstract}

\section{Anthony G. Charles,}

Department of Surgery, University of North Carolina, Chapel Hill, NC 27599, USA

Clara N. Lee,

Department of Surgery, University of North Carolina, Chapel Hill, NC 27599, USA

\section{Irving F. Hoffman,}

UNC Project, Private Bag A-104, Lilongwe, Malawi

Division of Infectious Diseases, Department of Medicine, University of North Carolina, Chapel Hill, NC 27599, USA

William C. Miller, Department of Epidemiology, School of Public Health, University of North Carolina, Chapel Hill, NC 27599, USA

Division of Infectious Diseases, Department of Medicine, University of North Carolina, Chapel Hill, NC 27599, USA

\section{Paul Baloyi,}

Department of Surgery, Kamuzu Central Hospital, P.O. Box 149, Lilongwe, Malawi

\section{Mariah Hoffman,}

UNC Project, Private Bag A-104, Lilongwe, Malawi

\section{Lillian B. Brown, and}

Department of Epidemiology, School of Public Health, University of North Carolina, Chapel Hill, NC 27599, USA

\section{Arturo P. Muyco}

Department of Surgery, Kamuzu Central Hospital, P.O. Box 149, Lilongwe, Malawi

Jonathan C. Samuel: jsamuel@unch.unc.edu

\section{Abstract}

(C) Société Internationale de Chirurgie 2009

Correspondence to: Jonathan C. Samuel, jsamuel@unch. unc.edu. 
Background-Injury surveillance is an ongoing process required for primary, secondary, and tertiary injury prevention. In Malawi, hospital-based injury data are not available.

Methods-From February to June 2008 we collected data on injured patients presenting to Kamuzu Central Hospital in Lilongwe, Malawi. The sample $(n=1,474)$ was predominantly male (75.7\%), and age distribution was bimodal (peak age groups $<5$ years and $26-30$ years). Roadtraffic injury (RTI) was the most common reason for treatment (43.4\%), followed by assault (24.0\%), which was more common than expected. The most common injuries were lacerations, contusions, and abrasions. We observed both gender- and age-specific patterns in injury mechanism: Injured females were more likely than injured males to have suffered an injury as a passenger in a car or on a bicycle, or to have suffered from falls, foreign bodies, and burns; injured males were more likely than injured females to have suffered an injury as an automobile driver or bicyclist, or from an assault. Falls, burns, and foreign bodies affected younger victims, whereas bicyclists, automobile drivers, and motorcycle operators were generally older persons.

Results-The hospital admission rate was $26.8 \%$. Most patients arrived by private vehicle (43.8\%), which was also the fastest means of transportation. There were 25 mass casualties leading to 102 admissions; all but one were due to RTIs, and seven were associated with at least one fatality.

Conclusions-This study elucidated injury epidemiology in Malawi and identified questions for future research. Other developing countries should conduct such prospective data collection to identify region-specific injury patterns and to promote injury prevention.

\section{Introduction}

Hospital-based trauma registries are an integral part of injury surveillance. A well-designed registry captures a spectrum of information including that related to the injury event (environment, behavior, demographics), the immediate period after the event (pre-hospital treatment and transportation), and the subsequent treatment and rehabilitation period (diagnoses, treatments, outcomes) $[1,2]$. This breadth of information is central to all facets of injury prevention: Event-related information is crucial to primary prevention; that pertaining to the period immediately after the event informs secondary prevention; knowledge of in-hospital and rehabilitation information guides tertiary prevention. In this context, registries are a continuous process, central to the design and evaluation of injury prevention efforts.

In 1966, the publication of Accidental Death and Disability: The Neglected Disease of Modern Society heralded the beginning of organized injury surveillance in the United States [3]. In the $1970 \mathrm{~s}$ data were collected and evaluated at single institutions or regionally, and this led to the development of trauma scoring systems [4, 5]. However, recognizing the need for aggregated data, the American College of Surgeons Committee on Trauma analyzed data from 139 U.S. hospitals in the Major Trauma Outcomes Study (MTOS) [6]. The MTOS resulted in more accurate predictive tools, and it allowed for comparisons of outcomes between hospitals using "trauma norms." Since the MTOS, many refinements have been made to scoring systems [7, 8], and these systems have been applied throughout the world $[9,10]$.

Low- and middle-income countries also benefit from trauma registries. Documenting the high burden of disease from injury in sub-Saharan Africa is one such application; the number of disability-adjusted life years lost from injury is ten times higher in the low- and middle-income African regions than in the high-income Americas [11]. In Uganda, a hospital-based trauma registry containing a range of information appropriate for all levels of injury prevention, referred to as a "minimal data set," has been used to address primary, 
secondary, and tertiary prevention-related data and appeared useful in a resource-constrained setting [12-14]. This registry provided the basis for a new scoring system, the Kampala Trauma Score (KTS), which performed well when validated against well-established systems such as the revised trauma score (RTS), injury severity score (ISS), and the trauma and injury severity score (TRISS) scoring systems $[15,16]$.

Malawi, a low-income country in the southeast region of sub-Saharan Africa, lacks both an organized trauma system and a national trauma registry. One of the first steps in addressing injuries in sub-Saharan Africa, including road traffic injuries, is solid data collection [1, 17, 18]. Therefore our objective was to implement a trauma registry to gather a minimal data set to better define injury epidemiology in Malawi. We hypothesized that these data would characterize traumatic injury in Lilongwe, including who gets injured, injury mechanisms, risk factors for injury, modes of transport and transport time, and the burden of mass casualties.

\section{Methods}

\section{Study setting}

This study was conducted at Kamuzu Central Hospital $(\mathrm{KCH})$ in Lilongwe, the capital of Malawi. With 625 beds, $\mathrm{KCH}$ is the referral center for the central region of Malawi (population of around 5 million). The hospital has a 24-h casualty department. Other resources include an intensive care unit, high dependency unit, radiology department, and four operating theaters. The hospital lacks a pathologist and does not have computed tomography or magnetic resonance imaging.

\section{Data collection}

Starting in February 2008, data were collected in a trauma registry on injured individuals admitted to $\mathrm{KCH}$ through the casualty department, those who died in the casualty department, and those brought in dead to the casualty department. The registry data included age, gender, address, occupation, location, time sequence of injury, mode of transport to the hospital, alcohol use, injury type(s) and body location(s), and disposition (admitted, dead on arrival, or died in casualty department). In April 2008, increased staffing and a new effort to collect more comprehensive information, it became possible to expand the data set to include all patients treated in the casualty department (not just those admitted) and to include mode of transport to the hospital.

Trained data entry clerks present $24 \mathrm{~h}$ a day collected the registry data. The clerks gathered data pertaining to the prehospital phase from the victim or those accompanying the victim. Clinical information including vital signs, injuries, and disposition, was collected from the clinician and recorded by the data entry clerk. The clerks used a data collection form, which consisted of a single, double-sided sheet of paper. The data were then entered into an electronic database in Microsoft Access (version 2007, Microsoft Inc., Redmond, WA), and analyzed using Stata (version 10.1).

\section{Data analysis}

We calculated gender and age distribution both overall and stratified by injury mechanism. After the data set was expanded in April 2008, we summarized patient disposition, and method of transportation to the hospital. For each method of transportation, we calculated the mean time from event to hospital arrival (pre-hospital time); of 922 data points, 62 outliers, defined as patients presenting longer than $24 \mathrm{~h}$ after the injury, were excluded. 
Characteristics of mass casualties, including the overall frequency, the mean number of individuals involved, the total number of resulting admissions, and the number of mass casualties resulting in at least one death, were calculated. Because the casualty department at $\mathrm{KCH}$ has only three examination beds, three or more patients at one time disrupt normal casualty department operations. A mass casualty was therefore defined as three or more individuals presenting for care of injuries resulting from the same event.

\section{Results}

Between February and June 2008 1,474 patients were captured in the registry. This included 259 patients during the first half of the study and 1,219 during the second half of the study (when outpatients were included). The study sample was predominantly male $(1,106$, or $75.7 \%$ ). The age distribution was bimodal (peak age groups $<5$ years and $26-30$ years; Fig. 1).

Table 1 shows the overall and gender-specific data on the most common mechanisms of injury and the median age for each category. Overall, the most common injury mechanism was road traffic injury (RTI), most often a passenger in an automobile. Road traffic injuries accounted for $43.4 \%$ of the total. After RTIs, assaults (24.0\%) and falls (13.5\%) were the most common injury mechanisms. Gender-specific data revealed that injured females were much more likely than injured males to have suffered an injury as a passenger in a car or on a bicycle, or to have suffered from falls, foreign bodies, and burns. In contrast, injured males were much more likely than injured females to have suffered an injury as an automobile driver or bicyclist, or from an assault. The median age associated with each injury mechanism also varied considerably: falls, burns, and foreign bodies affected younger persons, whereas bicyclists, automobile drivers, and motorcycle operators tended to be older.

Relatively minor injuries predominated, with contusions and abrasions (31.9\%) and lacerations (30.6\%) being the most common. Other injuries included fractures (14.3\%), head injuries (7.5\%), and burns (5.6\%).

There were 25 mass casualties during the 5-month study period. All were due to RTIs except for one, an assault of four alleged thieves by "mob justice." The number of individuals per mass casualty averaged 8.4 (range: 3-33), and the total number of admissions resulting from mass casualties in our study period was 102 . Seven (28\%) of the mass casualties involved one or more individuals brought in dead to the casualty department.

Data from the second portion of the study period (after inclusion of outpatients and mode of transport) revealed that most patients were treated and sent home $(69.7 \%)$, and a minority were admitted (26.8\%), brought in dead (3\%), or died in the casualty department $(0.5 \%)$. The most common mode of transport to the hospital was private vehicle (43.8\%), followed by ambulance (15.4\%), walking (14.5\%), minibus (public transport) (12.4\%) and police transport (7.8\%). Pre-hospital time varied by mode of transport, and overall averaged $3 \mathrm{~h}, 21$ $\min ($ Table 2).

\section{Discussion}

Our hospital-based trauma registry constructed from data collected in the casualty department, functioned well in a resource-constrained setting. Collecting information prospectively in the casualty department allowed for interviewing patients or their companions or family members, as well as care providers, immediately after the event, minimizing recall bias. Prospectively interviewing those accompanying the patient to the hospital also strengthened the collection of pre-hospital information such as transport modes 
and times, which are not recorded in patient charts and therefore are not obtainable with a retrospective review. Through prospective data collection we were also able to capture detailed outpatient information. We believe that these benefits of prospective data collection justify the additional expense associated with the required 24-h staffing of a data clerk.

One drawback of our approach was the lack of data on the outcomes of admitted patients. We therefore recommend that hospital-based surveillance efforts in low- and middle-income countries include not only prospective data collection in the casualty department (to inform primary and secondary intervention efforts), but also data collection on hospital care and outcomes of admitted patients. This approach would provide a comprehensive overview of injury informing primary, secondary, and tertiary prevention, which is possible only when both casualty department data and outcome data are combined.

The patient demographics in our registry are remarkably similar to the demographics of traumatically injured patients in the United States; the majority are young men and the most common injury mechanism is RTIs [19]. The age distribution that we observed, with a peak incidence in the under-5 age group and the 26-30 age group, is also similar to the United States, with one major exception; in the United States there is a third peak among 70-90year-olds due to an increased number of falls among persons in that age group [19]. We did not observe this, presumably because the short life expectancy in Malawi (41.1 years) results in few elderly sustaining falls.

The pattern of RTIs we observed - with pedestrians, bicyclists, and automobile passengers being the most affected-is similar to that in other countries in sub-Saharan Africa, with one exception; our proportion due to motorcycle injuries $(1.6 \%)$ was less than in other subSaharan countries, including Ghana (4\%) [20], Tanzania (3.5\%) [21], and Nigeria (36.2\%) [22]. This is likely because there are fewer motorcycle users in Malawi than in these other countries. Efforts should be directed at preventing injuries in the most at-risk groups, instead of targeting less at-risk groups such as motorcycle riders. For example, efforts such as provision of safety vests to motor cyclists, successful in other sub-Saharan countries, may have less impact in Malawi. Regardless of the particular intervention, what might be appropriate in one African country is not necessarily appropriate in another.

We identified demographic patterns relevant to designing prevention programs. For example, both age and gender were associated with specific injury mechanisms; injured females were more likely than injured males to be passengers in automobiles or on bicycles, whereas males were eight times more likely than females to be the drivers. Behavior modification is one method of injury prevention. Though interventions to improve driver and passenger safety should address both males and females, the patterns identified in our data indicate that modification of driver behavior (such as curbing aggressive driving) will have a greater impact among males, whereas modification of passenger behavior (such as encouraging seatbelt use) will have a greater impact among females.

Pre-hospital time in this registry was much longer than that in high-income countries such as the United States [23]. Shorter pre-hospital times are associated with more favorable outcomes [24]; thus decreasing transport time should be a priority. In our population we found that transport by private vehicle was much shorter than by ambulance; if a private vehicle is available, individuals should be encouraged to use this mode of transport rather than wait for an ambulance, which might lengthen transport time. One possible explanation for longer transport times associated with ambulance use is that ambulances are preferentially used for transport over greater distances, such as from outlying district hospitals, although this possibility requires further investigation. No matter what the causes of ambulance delay may be, there is no organized emergency response system in Malawi, 
such as the "911" system employed in the United States. Also, there is a shortage of ambulances within Lilongwe, which could explain why private vehicles transport three times as many patients as ambulances.

We observed a high rate of assaults (24.2\% of all injuries) compared to the United States, where RTIs (37.9\%) and falls (30.2\%) vastly outnumber assaults (12.0\%). Our assault rate was also higher than published data from a hospital-based registry in rural Ghana (5\%) [25], mortuary data from an urban region in Ghana (3\%) [26], and population-based data from both urban (3.4\%) and rural (0.9\%) Tanzania [27]. Given that the proportion of injuries from assault is fivefold that of surrounding countries, a better understanding of the nature of these assaults is crucial to addressing this problem and will be a focus of future research.

Because RTIs are the leading cause of injury, we intend to conduct future research to gain a better understanding of this problem. We plan to work with the National Road Safety Council (NRSC) of Malawi which currently bases all recommendations for RTI prevention solely on police report data. By working with the NRSC, we will combine our RTI data with police data to provide a more accurate picture of RTIs. Furthermore, such linkage analysis has been used in other developing countries to gain a more accurate assessment of RTI incidence through a "capturerecapture" method [28].

In summary, we found that prospective collection of injury data in a developing country was feasible and informative. We identified injury patterns pertinent to prevention. The registry data confirmed that RTIs are the leading cause of injury, and we plan to work with stakeholders such as the NRSC to address this. We also observed a surprisingly high rate of assaults, which will also be a target of future investigation. This study provides a framework for sound interventions and identifies future areas for research, which promotes the ultimate goal of minimizing morbidity and mortality from injuries. We strongly recommend that all countries prioritize such prospective data collection to better understand and mitigate the global burden of disease from injury.

\section{Acknowledgments}

The authors sincerely appreciate the work of the data collection and data entry clerks of Kamuzu Central Hospital. We gratefully acknowledge the University of North Carolina Department of Surgery, University of North Carolina Jaycee's Burn Center, and the University of North Carolina Project in Lilongwe, Malawi.

\section{References}

1. Mock C, Quansah R, Kobusingye O, et al. Trauma care in Africa: the way forward. Afr J Trauma. 2004; 2:53-58.

2. Jurkovich G, Mock C. Systematic review of trauma system effectiveness based on registry comparisons. J Trauma. 1999; 47:S46-S55. [PubMed: 10496611]

3. Mullins RA. historical perspective of trauma system development in the United States. J Trauma. 1999; 47:S8-S14. [PubMed: 10496604]

4. Sacco W, Milholland A, Ashman W, et al. Trauma indices. Comput Biol Med. 1977; 7:9-20. [PubMed: 844297]

5. Baker S, O'Neill B, Haddon W, et al. The injury severity score: a method for describing patients with multiple injuries and evaluating emergency care. J Trauma. 1974; 14:187-196. [PubMed: 4814394]

6. Champion H, Copes W, Sacco W, et al. The major trauma outcome study: establishing national norms for trauma care. J Trauma. 1990; 30:1356-1365. [PubMed: 2231804]

7. Offner P, Jurkovich G, Gurney J, et al. Revision of TRISS for intubated patients. J Trauma. 1992; 32:32-35. [PubMed: 1732571] 
8. Bergeron E, Rossignol M, Osler T, et al. Improving the TRISS methodology by restructuring age categories and adding comorbidities. J Trauma. 2004; 56:760-767. [PubMed: 15187738]

9. Scarpelini S, de Andrade J, Passos A. The TRISS method applied to the victims of traffic accidents attended at a tertiary level emergency hospital in a developing country. Sci Direct. 2006; 37:72-77.

10. Solagberu B, Adekanye A, Ofeogbu C, et al. Epidemiology of trauma deaths. West Afr J Med. 2003; 22:177-181. [PubMed: 14529233]

11. Peden, M.; McGee, K.; Krug, E. Geneva: World Health Organization; 2002. Injury: a leading cause of the global burden of disease.

12. Kobusingye O, Lett R. Hospital-based trauma registries in Uganda. J Trauma. 2000; 48:498-502. [PubMed: 10744292]

13. Kobusingye O, Guwatudde D, Owor G, et al. Citywide trauma experience in Kampala, Uganda: a call for intervention. Inj Prev. 2002; 8:133-136. [PubMed: 12120832]

14. Holder, Y.; Peden, M.; Krug, E., et al. Geneva: World Health Organization; 2001. Injury surveillance guidelines.

15. McLeod J, Kobusingye O, Frost C, et al. A comparison of the Kampala Trauma Score (KTS) with the Revised Trauma Score (RTS), Injury Severity Score (ISS), and the TRISS method in a Ugandan trauma registry. Eur J Trauma. 2003; 29:392-398.

16. Hochhausler A, Lindsell C, Johannigman J, et al. The Kampala Trauma Score, an easy tool for measuring injury severity in the emergency department. Acad Emerg Med. 2006; 13:S72.

17. Krug E. More people die on the roads than from Malaria, says WHO chief. Br Med J. 2002; 324:1116. [PubMed: 12003878]

18. Scurfield R. Poor quality data are major obstacle to improving road safety, says World Bank. Br Med J. 2006; 324:1116. [PubMed: 12003879]

19. Clark, D.; Fantus, R. Version 7.0. American College of Surgeons Committee on Trauma; 2007. National trauma data bank annual report 2007.

20. Mock C, Forjuoh S, Rivara F. Epidemiology of transport-related injuries in Ghana. Accid Anal Prev. 1999; 31:359-370. [PubMed: 10384229]

21. Museru L, Mcharo C, Leshabari M. Road traffic accidents in Tanzania: a ten year epidemiological appraisal. East Central Afr J Surg. 2002; 7:23-26.

22. Akinpelu O, Oladele A, Amusa Y, et al. Review of road traffic accident admissions in a Nigerian tertiary hospital. East Central Afr J Surg. 2007; 12:63-67.

23. Cornwell E, Belzberg H, Hennigan K, et al. Emergency medical services (EMS) vs non-EMS transport of critically injured patients. Arch Surg. 2000; 135:315-319. [PubMed: 10722034]

24. Feero S, Hedges J, Simmons E, et al. Does out-of-hospital EMS time affect trauma survival? Am J Emerg Med. 1995; 13:133-135. [PubMed: 7893293]

25. Mock C, Adzotor E, Denno D, et al. Admissions for injury at a rural hospital in Ghana: implications for prevention in the developing world. Am J Public Health. 1995; 85:927-931. [PubMed: 7604915]

26. London J, Mock C, Abantanga F, et al. Using mortuary statistics in the development of an injury surveillance system in Ghana. Bull WHO. 2002; 80:357-364. [PubMed: 12077610]

27. Moshiro C, Heuch I, Astrom A, et al. Injury epidemiology in an urban and a rural area in Tanzania: an epidemiological survey. BMC Public Health. 2005; 5:1-10. [PubMed: 15627405]

28. Tercero F, Andersson R. Measuring transport injuries in a developing country: an application of the capture-recapture method. Accid Anal Prev. 2004; 36:13-20. [PubMed: 14572822] 


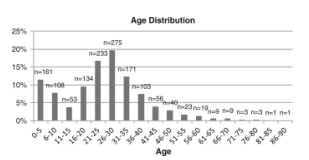

Fig. 1.

Age distribution of patients captured in the trauma registry 
Table 2

Most common modes of transport, including transport time

\begin{tabular}{lllll}
\hline Mode of transport & $\begin{array}{l}\text { Percent } \\
\text { of total }\end{array}$ & $\begin{array}{l}\text { Average transport } \\
\text { time (min) }\end{array}$ & $\begin{array}{l}\text { 95 percent confidence } \\
\text { interval (min) }\end{array}$ & $\begin{array}{l}\text { Percent arriving } \\
\text { within 1 h }\end{array}$ \\
\hline Private vehicle & 43.8 & 120 & $101-139$ & 48 \\
Ambulance & 15.4 & 312 & $245-378$ & 12 \\
Walked & 14.5 & 414 & $342-487$ & 11 \\
Minibus & 12.4 & 236 & $169-304$ & 33 \\
Police & 7.8 & 135 & $95-175$ & 45 \\
Company car & 3.3 & 79 & $55-103$ & 53 \\
Bicycle & 1.4 & 302 & $118-486$ & 18 \\
Other/unspecified & 1.2 & 227 & $27-428$ & 14 \\
Motorcycle & 0.2 & 304 & $76-532$ & 0 \\
\hline
\end{tabular}

World J Surg. Author manuscript; available in PMC 2012 February 29. 